\title{
Electro-photocatalytic degradation of acid orange II using a novel $\mathrm{TiO}_{2} / \mathrm{ACF}$ photoanode
}

\author{
Yining $\mathrm{Hou}^{a, b, 1}$, Juihui $\mathrm{Qu}^{a, *}, \mathrm{Xu} \mathrm{Zhao}^{a}$, Pengju Lei ${ }^{a}$, Dongjin Wan ${ }^{a, b}$, C.P. Huang ${ }^{c, *}$ \\ a State Key Laboratory of Environmental Aquatic Chemistry, Research Center for Eco-Environmental Sciences, Chinese Academy of Sciences, \\ P.O. Box 2871, Beijing 100085, China \\ ${ }^{\mathrm{b}}$ Graduate School, Chinese Academy of Sciences, Beijing 100039, China \\ ${ }^{c}$ Department of Civil and Environmental Engineering, University of Delaware, Newark, DE 19716, USA
}

\section{A R T I C L E D A T A}

\section{Article history:}

Received 25 April 2008

Received in revised form

1 December 2008

Accepted 5 December 2008

Available online 25 January 2009

\section{Keywords:}

Electro-photocatalysis

Activated carbon fibers

Titanium dioxide

Acid Orange II

Dye degradation

\begin{abstract}
A B S T R A C T
A novel photoanode was prepared by immobilizing $\mathrm{TiO}_{2}$ film onto activated carbon fibers $\left(\mathrm{TiO}_{2} / \mathrm{ACF}\right)$ using liquid phase deposition (LPD) to study the electro-photocatalytic (EPC) degradation of organic compounds exemplified by an azo-dye, namely, Acid Orange II (AOII). Results demonstrated that by applying a $0.5 \mathrm{~V}$ bias (vs. SCE) across the $\mathrm{TiO}_{2} / \mathrm{ACF}$ electrode, the AOII degradation rate was increased significantly compared to that of photocatalytic (PC) oxidation. The application of an electric field promotes the separation of photogenerated electrons and holes as confirmed by electrochemical impedance spectroscopy (EIS) measurements. The structural and surface morphology of the $\mathrm{TiO}_{2} / \mathrm{ACF}$ electrode was characterized by field emission scanning electron microscopy (FE-SEM) and X-ray diffraction (XRD). SEM images showed that $\mathrm{TiO}_{2}$ was deposited on almost every carbon fiber with an average thickness of about $200 \mathrm{~nm}$ with the inner space between neighboring fibers being maintained unfilled. The morphological features of the photo-anode facilitated the passage of solution as well as UV light through the felt-form electrode and created a threedimensional environment favorable to EPC oxidation. Both the large outer surface area of the 3D electrode and the good organic adsorption capacity of the ACF support promoted high contact efficiency between $\mathrm{AOII}$ and $\mathrm{TiO}_{2}$ surface. Anatase was the major crystalline $\mathrm{TiO}_{2}$ deposited. UV-vis spectrophotometry, TOC (total organic carbon) analysis, and HPLC technique were used to monitor the concentration change of AOII and intermediates as to gain insight into the EPC degradation of AOII using the $\mathrm{TiO}_{2} / \mathrm{ACF}$ electrode.
\end{abstract}

(C) 2008 Elsevier B.V. All rights reserved.

\section{Introduction}

The degradation of organic pollutants in water by the photocatalytic semiconductor $\mathrm{TiO}_{2}$ has attracted extensive attention in recent decades. Many researchers have reported that most refractory organic contaminants such as detergents, dyes, pesticides, and herbicides, can be decomposed by $\mathrm{TiO}_{2}$ under UV-light irradiation. It has been known also that conventional photooxidation has two major disadvantages: difficulty in solid-liquid separation and low photo-efficiency. For use in $\mathrm{TiO}_{2}$ suspension, extra effort is needed to separate the photocatalytic $\mathrm{TiO}_{2}$ particles from water. To deal with the

\footnotetext{
* Corresponding authors. Qu is to be contacted at State Key Laboratory of Environmental Aquatic Chemistry, Research Center for Eco-Environmental Sciences, Chinese Academy of Sciences, P.O. Box 2871, Beijing 100085, China. Tel: +86 1062849151 ; fax: +86 10 62923558. Huang, Department of Civil and Environmental Engineering, University of Delaware, Newark, DE 19716, USA. Tel: +1302 831 8428; fax: +1 3028313640.

E-mail addresses: yininghou1103@hotmail.com (Y. Hou), jhqu@rcees.ac.cn (J. Qu), huang@ce.udel.edu (C.P. Huang).

${ }^{1}$ Tel: +86 106284 9137; fax: +861062849160.
} 
problem of solid-liquid separation, fixed $\mathrm{TiO}_{2}$ systems where nano-sized $\mathrm{TiO}_{2}$ is immobilized onto solid surfaces such as glass (Addamo et al., 2008), ceramic membrane (Sabate et al., 1992), or steel plate (Takenori et al., 2000) has been suggested. Furthermore, conventional $\mathrm{TiO}_{2}$ photocatalysis has relatively low quantum yield (less than $10 \%$ generally) due to rapid hole-electron recombination. A high degree of recombination between charge carriers is a waste of radiation energy, especially when artificial rather than natural light sources are used. Intuitively, efficient separation of charge carriers can be achieved using an electrochemically assisted photocatalytic system, in which an electrical bias is applied across the photoanode, while the photogenerated electrons on the semiconductor such as $\mathrm{TiO}_{2}$ are pulling away from the photo-anode and fed to the cathode through an external electric circuit, thus inhibiting the hole-electron recombination. Immobilizing $\mathrm{TiO}_{2}$ on a hoto-node provides an ideal solution to the above technical deficiencies of conventional photocatalytic oxidation processes.

In many previous studies, photoanodes were generally prepared by coating $\mathrm{TiO}_{2}$ on a traditional plate electrode such as conducting glass (e.g. ITO) or titanium sheet (Palombari et al., 2002; Jiang et al., 2004; Quan et al., 2004; Li et al., 2005). This configuration is a two-dimensional (2D) arrangement that provides only limited adsorption sites for the chemical contaminants which affect subsequent electrophotodegradation of the chemical in question, as the degradation process is directly proportional to the specific surface area of the photoelectrode available. A three-dimensional (3D) photoelectrode would be a better configuration than that of a 2-D electrode. Under this context, activated carbon fibers (ACF) are ideal material for making 3-D electrodes (Fan et al., 2006). ACF is a highly micro-porous material and has high specific surface area and large pore volume, which can facilitate the adsorption of organic chemicals.

The objectives of this study were to test the hypothesis that the application of bias potential across the photoanode can enhance the photocatalytic oxidation process and that a three-dimensional (3D) instead of a two-dimensional (2D) photoanode configuration would be much efficient in the electro-photocatalytic oxidation of organic compounds. In this study, a novel photoanode was prepared by incorporating nano- $\mathrm{TiO}_{2}$ crystalline onto ACF. The electro-photocatalytic oxidation efficiency was assessed using Acid Orange II (AOII) as model organic contaminant. To the best of our knowledge, no such anode and its associated electro-photocatalytic characteristics have been reported in the literature.

\section{Experimental}

\subsection{Titanium dioxide film deposition}

Activated carbon fibers (ACF) in felt form (Xuesheng Technology Co. Ltd, Shandong Province, China), with a specific surface area of $1237 \mathrm{~m}^{2} / \mathrm{g}$, were used in this study. The ACF was pretreated in boiling water for $60 \mathrm{~min}$, air-dried overnight, and then hydroxylated by immersion in $1 \mathrm{M}$ of ammonium peroxydisulfate aqueous solution at $50{ }^{\circ} \mathrm{C}$ for $60 \mathrm{~min}$. The coating procedure, known as liquid phase deposition (LPD), was adopted from Koumoto et al. (1999) and Herbig and Löbmann (2004). In order to test the integrity of the $\mathrm{TiO}_{2}$ coating, the $\mathrm{TiO}_{2} / \mathrm{ACF}$ so prepared was placed in $100 \mathrm{~mL}$ of deionized water in a glass bottle and shaken (side-wide) at $150 \mathrm{rpm}$ for $12 \mathrm{~h}$. The turbidity of the deionized water was then determined with a turbidimeter (HACH 2100N, USA). Results indicated that there was no significant increase in turbidity of the deionized water. Briefly, ammonium hexafluorotitanate $\left(\left(\mathrm{NH}_{4}\right)_{2} \mathrm{TiF}_{6}(\mathrm{AHFT}), 1.176 \mathrm{~g}\right.$, C.P.) was dissolved in $84 \mathrm{~mL}$ of deionized water and mixed with $36 \mathrm{~mL}$ of boric acid $(0.5 \mathrm{M}$, $\mathrm{H}_{3} \mathrm{BO}_{3}$, A.R.) to form a solution containing $0.05 \mathrm{M}$ of AHFT and $0.15 \mathrm{M}$ of $\mathrm{H}_{3} \mathrm{BO}_{3}$. The addition of $2 \mathrm{M}$ of hydrochloric acid enabled the $\mathrm{pH}$ to be adjusted to 2.8 without significantly increasing the solution volume. The substrate, ACF, was vertically immersed in a freshly prepared deposition solution at $50{ }^{\circ} \mathrm{C}$ for $6 \mathrm{~h}$. Then the $\mathrm{TiO}_{2}$-coated ACF was removed from the solution, rinsed with deionized water, and air-dried overnight. Finally the samples were annealed at $350{ }^{\circ} \mathrm{C}$ in nitrogen atmosphere for $180 \mathrm{~min}$. In this study, the ACF loaded with $\mathrm{TiO}_{2}$ film was designated as $\mathrm{TiO}_{2} /$ ACF. The amount of $\mathrm{TiO}_{2}$ loading was estimated to be $\sim 5 \mathrm{wt} . \%$, which was determined from weight loss of the $\mathrm{TiO}_{2} / \mathrm{ACF}$ after calcination at $700{ }^{\circ} \mathrm{C}$ for $5 \mathrm{~h}$ in an air stream. (Note: it is expected that there is an optimal $\mathrm{TiO}_{2}$ loading necessary for the maximum degree of organic degradation by the electro-photocatalytic oxidation process.) The final $\mathrm{TiO}_{2} / \mathrm{ACF}$ electrode prepared was in the form of 3-mm felt. To compare the electro-photocatalytic efficiency of the 3D with that of the 2D photo-anode, another electrode was prepared by coating a thin film of $\mathrm{TiO}_{2}$ on a titanium sheet $\left(\mathrm{TiO}_{2} / \mathrm{Ti}\right)$ using the sol-gel method (Shang et al., 2003).

\subsection{Material characterization}

Surface characterization of $\mathrm{TiO}_{2} / \mathrm{ACF}$ was carried out by scanning electron microscopy (JSM-6301F, field emission scanning electron microscope, FE-SEM). Crystal phases were identified by automatic X-ray diffractometer (XRD, Rigaku D/ max-2500, Japan) with $\mathrm{CuK} \alpha$ radiation operated at $40 \mathrm{kV}$ and $20 \mathrm{~mA}$.

\subsection{Electro-photocatalytic degradation of Acid Orange II}

Degradation of Acid Orange II (AOII) was performed in a quartz reactor $\left(35 \mathrm{~mm} \times 35 \mathrm{~mm} \times 70 \mathrm{~mm}\right.$ ). $\mathrm{TiO}_{2} / \mathrm{ACF}$ (or $\mathrm{TiO}_{2} / \mathrm{Ti}$ ) was used as the photoanode with an effective working area of $12 \mathrm{~cm}^{2}$, which was placed at $2 \mathrm{~cm}$ away from a 15-w germicidal lamp ( $90 \%$ energy output at $253.7 \mathrm{~nm}$ ). Pt wire, $72 \mathrm{~mm}$ in length with a diameter of $1.5 \mathrm{~mm}$, was used as the counter electrode, and a saturated calomel electrode (SCE) was used as the reference electrode. The power source was an EG\&G model 263A potentiostat (Princeton Applied Research, USA). Electrochemical impedance spectra (EIS) were recorded in the potentiostatic mode. The amplitude of the sinusoidal wave was $10 \mathrm{mV}$, and the frequency of the sinusoidal wave was in the range from $0.1 \mathrm{~Hz}$ to $100 \mathrm{kHz}$.

The initial concentration of the An AOII solution was $200 \mathrm{mg} / \mathrm{L}$ (in $0.01 \mathrm{M}$ of sodium sulfate as supporting electrolyte). The solution was sampled periodically during reaction as to monitor the degree of AOII degradation by measuring 
the absorbance at $484 \mathrm{~nm}$ using a UV-vis spectrophotometer (Hitachi U-3010, Japan). The UV-vis spectra of the samples were recorded also from 190 to $600 \mathrm{~nm}$ as to observe intermediates that may be detectable by UV-visible spectrophotometry. Total organic carbon (TOC) was measured with a Phoenix 8000 TOC analyzer (Tekmar-Dohrmann Co., USA).

Separate experiments were run to study the concentration change of AOII and its degradation products using a high-performance liquid chromatograph (HPLC, Hitachi L2000, Japan). The initial concentration of AOII was $50 \mathrm{mg} / \mathrm{L}$ in $0.01 \mathrm{M}$ of sodium sulfate as supporting electrolyte. Aliquots of sample (e.g., $20 \mu \mathrm{L}$ ) were injected into the HPLC column running with the mobile phase of acetonitrile/water (0.025 M of ammonium acetate) at 35/65 (v/v). The separation was performed using an ODS-25u reversed phase column (Alltech, USA) at a flow rate of $1.0 \mathrm{~mL} / \mathrm{min}$ and column temperature of $40{ }^{\circ} \mathrm{C}$. Most of the aromatic intermediates detected in this study had strong absorbance at around $254 \mathrm{~nm}$, and thereafter a diode array detector was used to quantify the concentration of intermediates at this wavelength.

\section{Results and discussion}

\subsection{SEM and XRD analysis of $\mathrm{TiO}_{2} / \mathrm{ACF}$}

Fig. 1 shows typical SEM images of the $\mathrm{TiO}_{2} / \mathrm{ACF}$ as well as the unmodified ACF for comparison. The surface of the unmodified carbon fiber is full of long shallow grooves [Fig. 1a and b]. As shown in Fig. 1c and d, continuous $\mathrm{TiO}_{2}$ film was immobilized on almost every fiber of ACF. The


Fig. 1-SEM images of the $\mathrm{TiO}_{2} / \mathrm{ACF}$ and unmodified activated carbon fibers. (a) unmodified ACF at 500x; (b) single unmodified ACF at $5000 x$; (c) $\mathrm{TiO}_{2} / \mathrm{ACF}$ at $500 x$; (d) single activated fiber coated with $\mathrm{TiO}_{2}$ at $5000 \times$; (e) $\mathrm{TiO}_{2}$ coating at $50000 \times$; (f) cross-sectional view $\mathrm{ACF}$ with $\mathrm{TiO}_{2}$ coating at $30000 x$. 


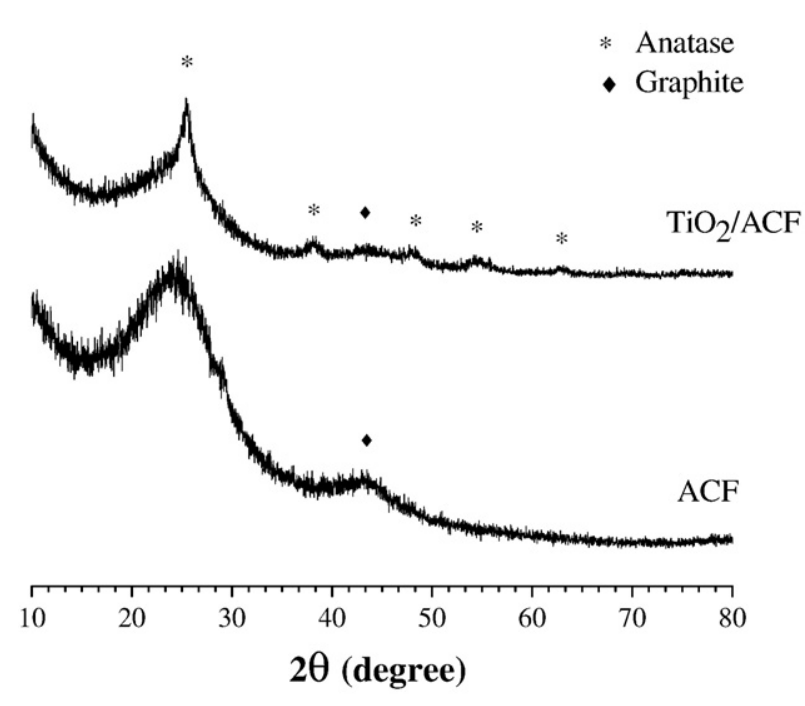

Fig. 2-XRD spectra of the unmodified $\mathrm{ACF}$ and $\mathrm{TiO}_{2} / \mathrm{ACF}$.

small spherical particles, sparsely attached to the film surface, were produced from $\mathrm{TiO}_{2}$ precipitation in solution. In spite of the high degree of $\mathrm{TiO}_{2}$ coating on the fibers, the $\mathrm{TiO}_{2} / \mathrm{ACF}$ retained the same spatial distribution as the unmodified ones; there were no adjacent fibers being connected to each other by the $\mathrm{TiO}_{2}$ particles deposited. Thus, the large inner space between neighboring fibers created a 3-D environment that could enable the transport of chemical species in question and UV irradiation. This distinct feature (i.e., felt form) makes the $\mathrm{TiO}_{2} / \mathrm{ACF}$ photoanode different from that of the plate type electrodes such as $\mathrm{TiO}_{2} / \mathrm{ITO}$ and $\mathrm{TiO}_{2} / \mathrm{Ti}$, which can provide only limited twodimensional surface for photodegradation. The image of the $\mathrm{TiO}_{2}$ coating was further enlarged to show details of the morphology of its surface [Fig. 1e]. The coated $\mathrm{TiO}_{2}$ layer did not form compact configuration on the ACF surface. Rather small clusters of $\mathrm{TiO}_{2}$ crystals spread over the ACF surface with irregular shape, and the interstices among crystalline particles provide an ideal passageway for the transport and adsorption of organic molecules such as AOII which molecular dimension is $1.24 \times 0.68 \times 0.22 \mathrm{~nm}$ (Tamai et al., 1996). From the cross-sectional view of the $\mathrm{TiO}_{2}$ film shown in Fig. 1f, the film thickness was estimated to be about $200 \mathrm{~nm}$.

Fig. 2 shows the XRD spectra of the unmodified ACF and $\mathrm{TiO}_{2} / \mathrm{ACF}$. The peaks of $\mathrm{TiO}_{2} / \mathrm{ACF}$ at $25.4^{\circ}, 38.2^{\circ}, 47.9^{\circ}, 54.8^{\circ}$ and $62.6^{\circ}$ are related to the diffractions of the (101), (112), (200), (211), and (204) planes of anatase $\mathrm{TiO}_{2}$. No significant diffraction peaks of rutile-phase $\mathrm{TiO}_{2}$ were detected in the XRD spectra. The broad peak at $43.4^{\circ}$ of the unmodified ACF represents both the (100) and (101) planes of graphite. This typical peak still appears in the XRD spectra of $\mathrm{TiO}_{2} / \mathrm{ACF}$, which means that the microstructure of ACF is not altered upon the deposition of $\mathrm{TiO}_{2}$ and the subsequent calcination at high temperature.

\subsection{Cyclic voltammetry and electrochemical impedance spectroscopy analysis of $\mathrm{TiO}_{2} / \mathrm{ACF}$}

Fig. 3 shows the cyclic voltammetry scans of sodium sulfate (0.01 M) solution without and with $200 \mathrm{mg} / \mathrm{L}$ of AOII, respectively, using the $\mathrm{TiO}_{2} / \mathrm{ACF}$ electrode. An increase in anodic current was clearly observable under UV illumination compared to that under dark conditions. This can be attributed to the anodic bias applied to the $\mathrm{TiO}_{2} / \mathrm{ACF}$ electrode, which provides a potential gradient across the $\mathrm{TiO}_{2}$ film. The potential gradient can enhance the transport of photogenerated electrons on the $\mathrm{TiO}_{2}$ film efficiently through the external circuit to the counter electrode, thus producing additional anodic photocurrent under UV light (Vinodgopal et al., 1993; Zanoni et al., 2003). Under UV irradiation, the photocurrent of the sodium sulfate $(0.01 \mathrm{M})$ solution without AOII was higher than that of the same electrolyte with $200 \mathrm{mg} / \mathrm{L}$ of AOII. This is attributed to the UV light blockage by the orange color of AOII at high concentrations. Similarly, under dark conditions, the addition of $200 \mathrm{mg} / \mathrm{L}$ of AOII also created a slight drop in the anodic current, which could be caused by the adsorption of AOII onto the $\mathrm{TiO}_{2} / \mathrm{ACF}$ surface. Adsorption of AOII on the photoanode may affect its electric conductivity to some extent. Moreover, the dark current in the sodium sulfate

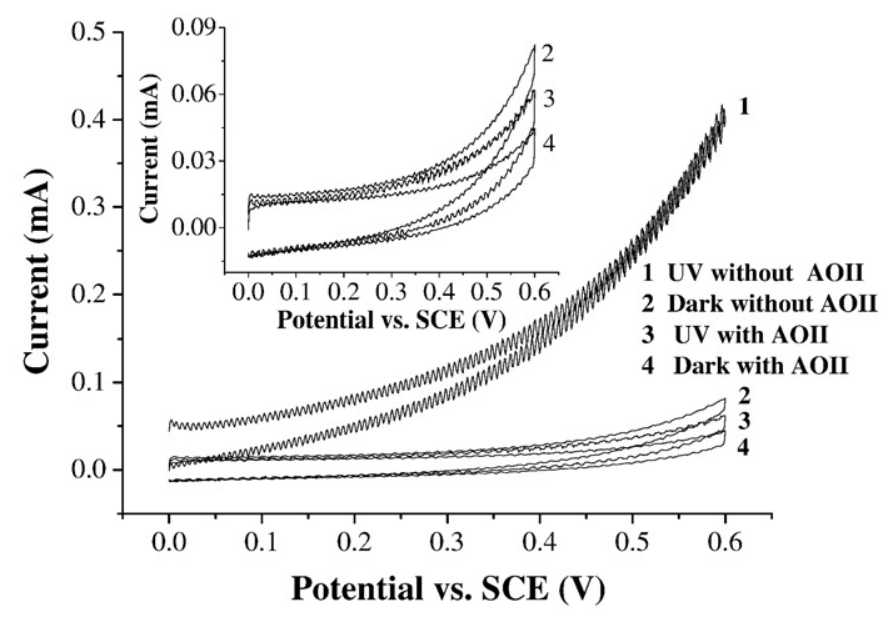

Fig. 3-Cyclic voltammetric scans of $\mathrm{TiO}_{2} / \mathrm{ACF}$ in $0.01 \mathrm{M}$ of sodium sulfate electrolyte with and without the presence of $200 \mathrm{mg} / \mathrm{L}$ of AOII under UV illumination and in dark (scan rate $=10 \mathrm{mV} / \mathrm{s}$, scan range $=0.0-0.6 \mathrm{~V} \mathrm{vs}$. SCE). 


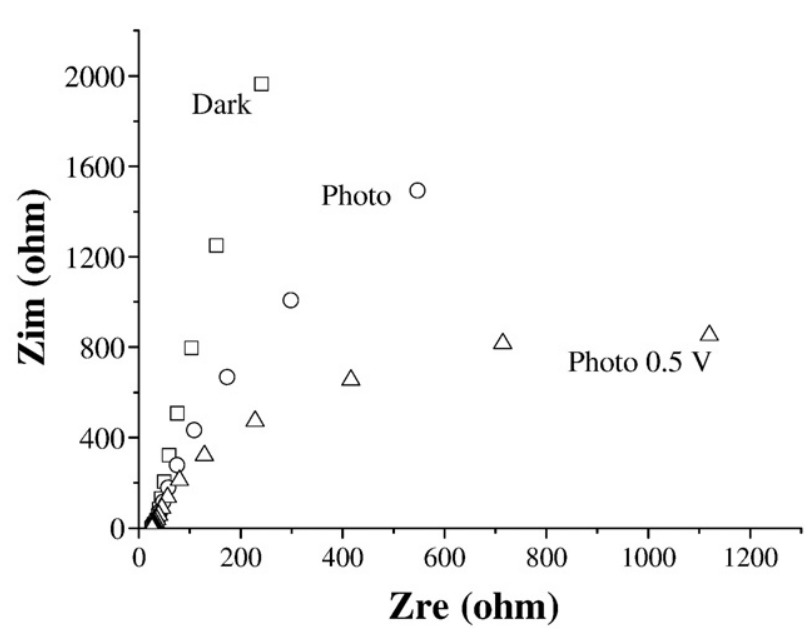

Fig. 4-Effect of photoirradiation and the bias potential on the EIS plane display of the degradation of $\mathrm{AOII}$ at $\mathrm{TiO}_{2} / \mathrm{ACF}$ (the amplitude of the sinusoidal wave was $10 \mathrm{mV}$, and the frequency of the sinusoidal wave was in the range of $0.1 \mathrm{~Hz}$ to $100 \mathrm{kHz})$.

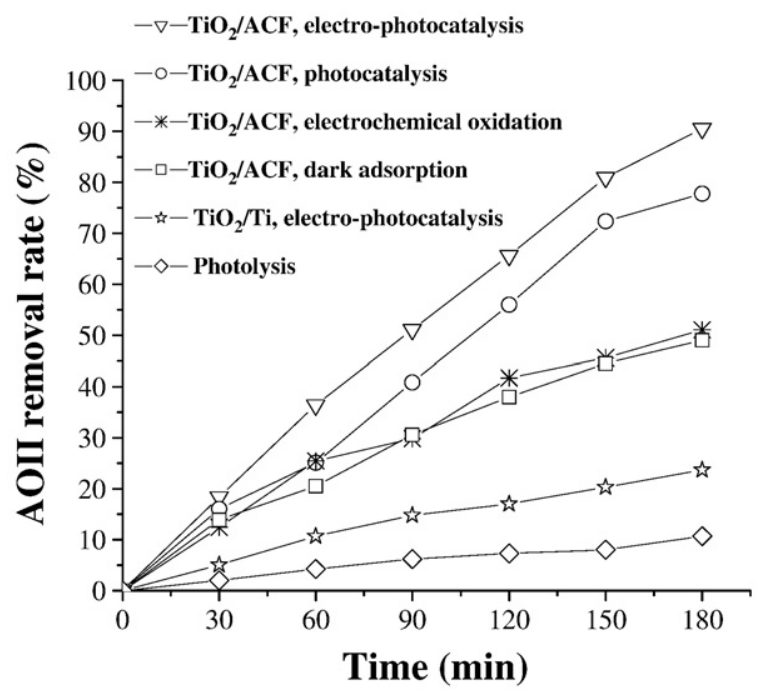

Fig. 5-Comparing the treatment of AOII by various methods including EPC, PC, electrochemical oxidation and adsorption in dark. The initial concentration of AOII was $200 \mathrm{mg} / \mathrm{L}$, the light source as applicable was $15 \mathrm{w} \mathrm{UV}_{254}$ lamp, and the electrical bias as applicable was $0.5 \mathrm{~V}$.

solution increased and then decreased steadily as a function of the electrical potential applied. No oxygen evolution was observed at the anode between 0 and $0.6 \mathrm{~V}$ vs. SCE. Since reactive oxygen species (ROSs) cannot be formed without oxygen evolution, clearly there was no indirect electrooxidation of AOII. With regard to the solution containing $200 \mathrm{mg} / \mathrm{L}$ of AOII without photoirradation, over the same bias range as above, neither oxidation nor reduction peaks were observed in the cyclic voltammogram. Furthermore, the anodic current was comparatively weak under the present experimental conditions. Therefore, direct electro-oxidation of AOII on the $\mathrm{TiO}_{2} / \mathrm{ACF}$ electrode was not expected.

Electrochemical impedance spectroscopy (EIS) is a powerful tool to study the electro-photocatalytic activity on $\mathrm{TiO}_{2}$ electrode (Leng et al., 2005). EIS measurements were carried out covering the frequency range of $0.1 \mathrm{~Hz}$ and $100 \mathrm{kHz}$ using a potential of $10 \mathrm{mV}$. Fig. 4 shows the EIS responses of the $\mathrm{TiO}_{2} / \mathrm{ACF}$ electrode under dark condition, photoirradiation, and combined photoirradiation and applied bias potential. It is clear that the curvature of the arc of the EIS Nyquist plot increased (or radius reduced) due to photoirradiation. Liu et al. (2000) and Leng et al. (2005) suggested that the curvature of the arc of the EIS Nyquist plot was a reflection of the reaction rate at the electrode surface. The results confirmed that photoirradiation enhanced the degradation rate of AOII. Photoirradiation and the application of $0.5 \mathrm{~V}$ of bias potential increased the curvature of the arc further compared with that of the photoirradiation-only condition. This means that effective separation of the photogenerated electronhole pairs and fast interfacial charge transfer to the electron donor/electron acceptor took place as suggested by Leng et al. (2005). Thus, electro-photocatalytic process can degrade AOII effectively. In addition, only one arc was observed on the Nyquist plot, which implies that both photocatalysis (PC) and electro-photocatalysis (EPC) are simple electrode processes (Liu et al., 2000; Zhao et al., 2007).

\subsection{EPC degradation of AOII}

For comparison, four other AOII removal processes, namely, photolysis, photocatalysis, electrochemical oxidation, and dark adsorption, in addition to EPC, were also tested. Fig. 5 and Table 1 show the results of the removal of AOII by the above processes. The adsorption experiment was conducted in dark without either electrical bias or photo-illumination. In EPC and electrochemical oxidation runs, the applied bias potential was kept constant at $0.5 \mathrm{~V}$, whereas no electrical bias was applied to the $\mathrm{TiO}_{2} / \mathrm{ACF}$ electrode in the $\mathrm{PC}$ oxidation experiments. It can be seen that the degradation of AOII by UV irradiation, i.e., photolysis, was not effective. The significant AOII removal by adsorption on $\mathrm{TiO}_{2} / \mathrm{ACF}$ in dark could be attributed to its high specific surface area $\left(\mathrm{S}_{\mathrm{BET}}\right)$ originating from the ACF support. However, with the filling of AOII in the

Table 1 - The removal of Acid Orange II by various methods at reaction time of $\mathbf{1 8 0}$ min

Processes Photolysis Dark adsorption Electrochemical oxidation $\quad \mathrm{PC}^{\mathrm{a}}\left(\mathrm{TiO}_{2} / \mathrm{ACF}\right) \quad \mathrm{EPC}^{\mathrm{b}}\left(\mathrm{TiO}_{2} / \mathrm{ACF}\right) \quad \mathrm{EPC}^{\mathrm{b}}\left(\mathrm{TiO}_{2} / \mathrm{Ti}\right)$ $\left(\mathrm{TiO}_{2} / \mathrm{ACF}\right)$

$\left(\mathrm{TiO}_{2} / \mathrm{ACF}\right)$

\begin{tabular}{lllllll}
\hline Removal & 10.7 & 49.1 & 51.1 & 77.8 & 90.5 & 23.7
\end{tabular}

percentage (\%)

a Photocatalysis.

b Electro-photocatalysis. 


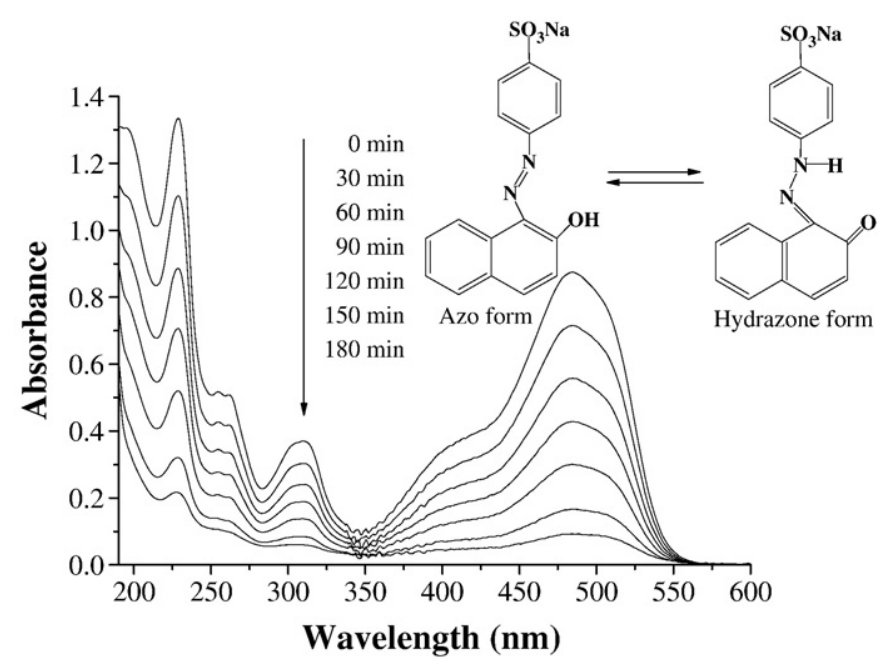

Fig. 6-UV-vis spectral changes as a function of reaction time during the EPC process on $\mathrm{TiO}_{2} / \mathrm{ACF}$. The initial concentration of AOII was $200 \mathrm{mg} / \mathrm{L}$, the light source was $15 \mathrm{w} \mathrm{UV}_{254}$ lamp, and the electrical bias applied was $0.5 \mathrm{~V}$.

micropores of ACF, it is expected that ACF will gradually lose its adsorption capacity. The degradation rate of AOII by electrochemical oxidation was almost parallel to that of adsorption, which implied that electrochemical oxidation did not contribute to the degradation of AOII at any significant level. The electro-photocatalysis, EPC, i.e., electrochemically assisted photocatalysis, rather than the combined process of electrochemical and photocatalytic oxidation, is the major process responsible for the degradation of AOII. Results shown in Fig. 5 clearly demonstrate that the EPC process using the $\mathrm{TiO}_{2} / \mathrm{ACF}$ electrode yielded the best AOII degradation among all processes studied. AOII removal by EPC was much higher than that of photolysis, adsorption, and electrochemical oxidation.

The efficiency of heterogeneous reaction depends on the frequency and efficiency of collision between the catalyst



Fig. 7-The removal of TOC and AOII by EPC and by adsorption in dark using $\mathrm{TiO}_{2} / \mathrm{ACF}$. The initial concentration of AOII was $200 \mathrm{mg} / \mathrm{L}$, the light source was 15 w UV 254 lamp, and the electrical bias applied was $0.5 \mathrm{~V}$. surface and the chemical species in the bulk solution (Kudo and Hijii, 1999). In the present EPC process, the threedimensional $\mathrm{TiO}_{2} / \mathrm{ACF}$ electrode offered a large contact surface area, and by virtue of strong adsorption, AOII molecules were concentrated in the $\mathrm{TiO}_{2} / \mathrm{ACF}$ matrix. This would increase the transfer of localized AOII molecules toward the neighboring $\mathrm{TiO}_{2}$ surface per the concentration gradient created therewith. At the interface between $\mathrm{TiO}_{2}$ and ACF, AOII molecules reacted with the photogenerated oxidizing species and were decomposed readily (Yuan et al., 2005). Photodecomposition of adsorbed AOII molecules refreshed

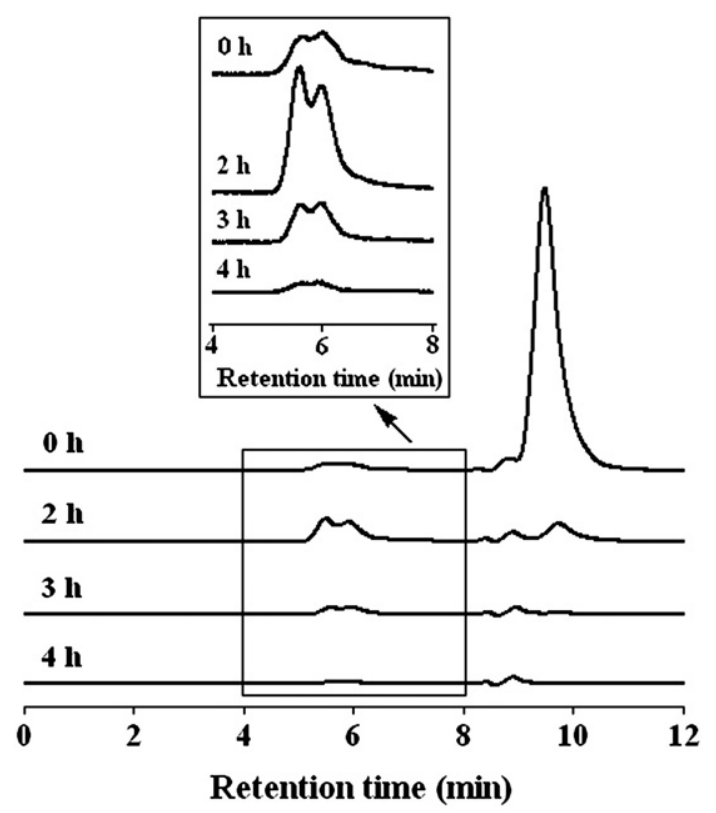

Fig. 8-The HPLC chromatogram of the AOII solution treated by the EPC process on $\mathrm{TiO}_{2} / \mathrm{ACF}$. The initial concentration of AOII was $50 \mathrm{mg} / \mathrm{L}$, the light source was $15 \mathrm{w} \mathrm{UV}_{254}$ lamp, and electrical bias applied was $0.5 \mathrm{~V}$. 
the adsorption sites on the $\mathrm{TiO}_{2} / \mathrm{ACF}$ matrix constantly, which allowed further adsorption of AOII and facilitated the electrophotocatalysis of AOII on the $\mathrm{TiO}_{2}$ film (Fu et al., 2004). Likewise, in the PC process, the adsorption of AOII on the ACF support also improved the collision efficiency between AOII and the $\mathrm{TiO}_{2}$ surface. In the absence of an electrical bias, the recombination rate of photogenerated electron-hole pairs was higher than that of the EPC process. As a result, the photodegradation rate of AOII by PC was lower than that by EPC. Up to $91 \%$ of AOII removal was observed using the EPC process, whereas the PC process only removed $78 \%$ of AOII under the same illumination period of $180 \mathrm{~min}$. Moreover, large outer surface and good adsorption capacity for AOII, the $3 \mathrm{D} \mathrm{TiO}_{2} / \mathrm{ACF}$ exhibited much greater AOII degradation than the $2 \mathrm{D} \mathrm{TiO}_{2} / \mathrm{Ti}$ electrode.

Fig. 6 shows the UV-vis spectral changes of AOII solution during EPC treatment using the $\mathrm{TiO}_{2} / \mathrm{ACF}$ electrode, with the tautomeric profile of AOII illustrated in the inset. AOII has four absorption bands, with two in the visible region and two in the ultraviolet region. In the visible region, a major band at $484 \mathrm{~nm}$ and a shoulder band at $430 \mathrm{~nm}$ due to the hydrazone and the azo form of AOII, respectively, were observed. The other two bands, at 230 and $310 \mathrm{~nm}$ in the ultraviolet region, are attributed to the benzene and the naphthalene rings of the dye, respectively (Wu et al., 2000; Stylidi et al., 2003). All four absorption bands diminished steadily with increase in reaction time, which indicated that the four characteristic structures of the dye molecule were photodegraded simultaneously.

In any advanced chemical oxidation system such as EPC, it is important to know both the degree of the decomposition of the parent compound and that of mineralization. In this study, the degree of mineralization was measured in terms of the change of TOC. Fig. 7 shows the percentage of TOC removal


Fig. 9-Conceptual presentation of the degradation of $\mathrm{AOII}$ by EPC over the $\mathrm{TiO}_{2} / \mathrm{ACF}$ surface. 
with respect to reaction time by EPC and by adsorption in dark using $\mathrm{TiO}_{2} / \mathrm{ACF}$. According to Fig. 7, the extent of AOII removal by adsorption in dark was similar to that of TOC removal. Since no AOII decomposition took place, the amount of AOII adsorbed onto $\mathrm{TiO}_{2} / \mathrm{ACF}$ was the same as that of TOC removed. A major difference can be seen by comparing the percentage of AOII removal with that of TOC removal by the EPC process. The degree of mineralization was lower than that of the decomposition of AOII, which is not uncommon in heterogeneous catalysis (Fernandes et al., 2004; Li et al., 2006; Murugananthan et al., 2007). The cleavage of the AOII molecular structure first occurs at positions that are susceptible to free radical attack with the production of various intermediates. This step is followed by further radical attack of the intermediates to yield $\mathrm{CO}_{2}$ and oxyanions such as nitrate and sulfate. Although the percent TOC removal by EPC was close to that of adsorption in dark, the organic components contributing to TOC in these two solutions were different. In the adsorption system, TOC was contributed totally from the original dye, i.e., AOII, present, whereas in the EPC system, in addition to the residual AOII per se, the organic intermediates evolved from the electro-photocatalytic degradation of AOII contributed to TOC as well. Moreover, the degree of mineralization by the EPC system exceeded that of adsorption in dark at time greater than $120 \mathrm{~min}$.

In order to better understand EPC degradation using $\mathrm{TiO}_{2} /$ ACF, the decay of AOII and the evolution of intermediates were followed by HPLC measurements. Fig. 8 shows the chromatogram of the AOII treated by the EPC at various time periods. Based on the well-developed (major) peak at the retention time of $9.7 \mathrm{~min}$, which is correspondent to the parent compound, it is seen that AOII underwent remarkably efficient degradation by EPC using the $\mathrm{TiO}_{2} / \mathrm{ACF}$ electrode, achieving $95 \%$ removal within the first $120 \mathrm{~min}$. Concomitant with the decomposition of AOII, a group of intermediates with retention time around $6 \mathrm{~min}$ were detected. These intermediates appeared during the first few hours; after reaching the peak values at about $120 \mathrm{~min}$, the peaks diminished along with AOII as the reaction time was extended. The inset of Fig. 8 shows clearly that these intermediates might also be present in the original AOII solution in comparatively small amounts. This could be that the intermediates detected by HPLC happened to be the minor organic impurities of the AOII used, too. Nonetheless, the impurities and newly formed intermediates were both degraded by the electro-photocatalytic $\mathrm{TiO}_{2} / \mathrm{ACF}$. After $240 \mathrm{~min}$ of photoirradiation, the concentration of the intermediates was insignificant.

Fig. 9 presents the conceptual reaction pathway of the electro-photocatalytic degradation of AOII over $\mathrm{TiO}_{2} / \mathrm{ACF}$. First, AOII molecules diffused to the vicinity of the $\mathrm{TiO}_{2} / \mathrm{ACF}$ surface and became absorbed into the micropores of ACF. The adsorbed dye molecules subsequently were transferred by surface diffusion to the interface between $\mathrm{TiO}_{2}$ and ACF, where photodegradation took place to yield intermediates. A fraction of the intermediates continued to be adsorbed on the $\mathrm{TiO}_{2} / \mathrm{ACF}$ surface and underwent photodecomposition until they were mineralized to $\mathrm{CO}_{2}$ or other inorganic ions, whereas some of the intermediates went through a desorptionadsorption process until they became totally mineralized. In addition, the recombination of the photoinduced electron- hole pairs was suppressed efficiently by applying an external electric field. The electrons were transferred to the cathode through the external circuit, and the remaining active holes could oxidize the organics or react with $\mathrm{H}_{2} \mathrm{O}$ and $\mathrm{OH}^{-}$to form $\mathrm{OH}$ radicals. It is known that $\mathrm{OH}$ radicals are strong oxidants that react with organic or inorganic compounds without selectivity.

\section{Conclusions}

A coherent $\mathrm{TiO}_{2}$ film of the anatase type was deposited successfully on activated carbon fibers by liquid phase deposition (LPD) method followed by calcination at $350{ }^{\circ} \mathrm{C}$ in nitrogen atmosphere. The microstructure and surface properties of ACF remained intact during the deposition process. An enhanced photocatalytic degradation of AOII was achieved by applying a $0.5-\mathrm{V}$ bias across the $\mathrm{TiO}_{2} / \mathrm{ACF}$ electrode under UV illumination, which is known as the electro-photocatalytic (EPC) process. In the EPC process, the applied bias was not intended to create electrochemical oxidation of AOII because the potential applied was relatively low, which could generate only a weak anodic current. The applied bias was low but was sufficiently high enough to inhibit the recombination of holes and electrons efficiently and promoted AOII degradation as confirmed by EIS measurements. Additionally, the threedimensional $\mathrm{TiO}_{2} / \mathrm{ACF}$ electrode has large outer surface area along with good adsorption capacity for organic compounds, which improved the contact efficiency between the organic contaminants in question and the $\mathrm{TiO}_{2}$ surface and ultimately enhanced the EPC activity. Over a reaction time of $180 \mathrm{~min}$, it is possible to remove $91 \%$ of AOII at an initial concentration of $200 \mathrm{mg} / \mathrm{L}$; the percent AOII removal was 95\% in $120 \mathrm{~min}$ when the initial concentration was $50 \mathrm{mg} /$, however. Moreover, large outer surface and good adsorption capacity for AOII, the 3D $\mathrm{TiO}_{2} / \mathrm{ACF}$ exhibited much greater AOII degradation than the 2D $\mathrm{TiO}_{2} / \mathrm{Ti}$ electrode. A group of intermediates sensitive to HPLC analysis during the EPC decomposition of AOII was detected. The intermediates reached peak production in about $120 \mathrm{~min}$, and then decreased upon further increase in reaction time.

\section{Acknowledgements}

This project was supported by research grants No. 50538090 and No. 50621804 from the National Natural Science Foundation of China and the Funds for Creative Research Groups of China. We wish to thank Diane Kukich, University of Delaware, for her editorial assistance.

\section{R E F E R E N C E S}

Addamo M, Augugliaro V, Di Paola A, García-López E, Loddo V, Marcì G, et al. Photocatalytic thin films of $\mathrm{TiO}_{2}$ formed by a sol-gel process using titanium tetraisopropoxide as the precursor. Thin Solid Films 2008;516:3802-7. 
Fan L, Zhou YW, Yang WS, Chen GH, Yang FL. Electrochemical degradation of Amaranth aqueous solution on ACF. J Hazard Mater B 2006;137:1182-8.

Fernandes A, Morão A, Magrinho M, Lopes A, Gonçalves I. Electrochemical degradation of C.I. Acid Orange 7. Dyes Pigm 2004;61:287-96.

Fu PF, Luan Y, Dai XG. Preparation of activated carbon fibers supported $\mathrm{TiO}_{2}$ photocatalyst and evaluation of its photocatalytic reactivity. J Mol Catal A Chem 2004;221:81-8.

Herbig B, Löbmann $\mathrm{P}$. $\mathrm{TiO}_{2}$ photocatalysts deposited on fiber substrates by liquid phase deposition. J Photochem Photobiol A Chem 2004;163:359-65.

Jiang DL, Zhao HJ, Zhang SQ John R. Kinetic study of photocatalytic oxidation of adsorbed carboxylic acids at $\mathrm{TiO}_{2}$ porous films by photoelectrolysis. J Catal 2004;223:212-20.

Koumoto K, Seo S, Sugiyama T, Seo WS. Micropatterning of titanium dioxide on self-assembled monolayers using a liquid-phase deposition process. Chem Mater 1999;11:2305-9.

Kudo A, Hijii S. $\mathrm{H}_{2}$ or $\mathrm{O}_{2}$ evolution from aqueous solutions on layered oxide photocatalysts consisting of $\mathrm{Bi}^{3+}$ with $6 \mathrm{~s}^{2}$ configuration and $\mathrm{d}^{0}$ transition metal ions. Chem Lett 1999;28:1103-4.

Leng WH, Zhang Z, Zhang JQ Cao CN. Investigation of the kinetics of a $\mathrm{TiO}_{2}$ photoelectrocatalytic reaction involving charge transfer and recombination through surface states by electrochemical impedance spectroscopy. J Phys Chem B 2005;109:15008-23.

Li XZ, He C, Graham N, Xiong Y. Photoelectrocatalytic degradation of bisphenol $\mathrm{A}$ in aqueous solution using a $\mathrm{Au}-\mathrm{TiO}_{2} / \mathrm{ITO}$ film. J Appl Electrochem 2005;35:741-50.

Li GT, Qu JH, Zhang XW, Liu HJ, Liu HN. Electrochemically assisted photocatalytic degradation of Orange II: Influence of initial $\mathrm{pH}$ values. J Mol Catal A Chem 2006;259:238-44.

Liu H, Cheng SA, Wu M, Wu HJ, Zhang JQ Li WZ, et al. Photoelectrocatalytic degradation of sulfosalicylic acid and its electrochemical impedance spectroscopy investigation. J Phys Chem A 2000;104:7016-20.

Murugananthan M, Yoshihara S, Rakuma T, Uehara N, Shirakashi T. Electrochemical degradation of $17 \beta$-estradiol (E2) at boron-doped diamond (Si/BDD) thin film electrode. Electrochim Acta 2007;52:3242-9.
Palombari R, Ranchella M, Rol C, Sebastiani GV. Oxidative photoelectrochemical technology with $\mathrm{Ti} / \mathrm{TiO}_{2}$ anodes. Sol Energy Mater Sol Cells 2002;71:359-68.

Quan X, Chen S, Su J, Chen JW, Chen GH. Synergetic degradation of 2,4-D by integrated photo- and electrochemical catalysis on a Pt doped $\mathrm{TiO}_{2} /$ Ti electrode. Sep Purif Technol 2004;34:73-9.

Sabate J, Anderson MA, Kikkawa H, Xu Q Cervera-March S, Hill CG. Nature and properties of pure and $\mathrm{Nb}$-doped $\mathrm{TiO}_{2}$ ceramic membranes affecting the photocatalytic degradation of 3-chlorosalicylic acid as a model of halogenated organic compounds. J Catal 1992;134:36-46.

Shang J, Li W, Zhu YF. Structure and photocatalytic characteristics of $\mathrm{TiO}_{2}$ film photocatalyst coated on stainless steel webnet. J Mol Catal A Chem 2003;202:187-95.

Stylidi M, Kondarides DI, Verykios XE. Pathways of solar-light induced photocatalytic degradation of azo dyes in aqueous $\mathrm{TiO}_{2}$ suspensions. Appl Catal B Environ 2003;40:271-86.

Takenori D, Kiyohisa I, Mitsunobu I, Hiroaki T, Seishiro I. Photocatalytically highly active nanocomposite films consisting of $\mathrm{TiO}_{2}$ particles and $\mathrm{ZnO}$ whiskers formed on steel plates. J Electrochem Soc 2000;147:2263-7.

Tamai H, Kakii T, Hirota Y, Kumamoto T, Yasuda H. Synthesis of extremely large mesoporous activated carbon and its unique adsorption for giant molecules. Chem Mater 1996;8:454-62.

Vinodgopal K, Hotchandani S, Kamat PV. Electrochemically assisted photocatalysis: titania particulate film electrodes for photocatalytic degradation of 4-chlorophenol. J Phys Chem 1993;97:9040-4.

Wu F, Deng NS, Hua HL. Degradation mechanism of azo dye C.I. reactive red 2 by iron powder reduction and photooxidation in aqueous solutions. Chemosphere 2000;41:1233-8.

Yuan RS, Guan RB, Shen WZ, Zheng JT. Photocatalytic degradation of methylene blue by a combinationof $\mathrm{TiO}_{2}$ and activated carbon fibers. J Colloid Interface Sci 2005;282:87-91.

Zanoni MVB, Sene JJ, Anderson MA. Photoelectrocatalytic degradation of Remazol Brilliant Orange 3R on titanium dioxide thin-film electrodes. J Photochem Photobiol A Chem 2003;157:55-63.

Zhao X, Xu TG, Yao WQ Zhang C, Zhu YF. Photoelectrocatalytic degradation of 4-chlorophenol at $\mathrm{Bi}_{2} \mathrm{WO}_{6}$ nanoflake film electrode under visible light irradiation. Appl Catal B Environ 2007;72:92-7. 